\title{
P48 CARE TEAM VOLUNTEERS
}

Wendy Bridge, Kate Barklie, Sarah Westmorland, Amelia Cook Helen \& Douglas House Hospice, Oxford, England

10.1136/bmjspcare-2011-000105.48

Introduction As a hospice for children and young adults we wanted to find creative, cost effective ways to enrich patient lives, using volunteers as befrienders to promote normalisation which research shows is a priority for this population.

Aims We aimed to recruit befriending volunteers with a developed skills set, to ensure flexibility and enhance patient experience. We aimed to set up systems to recruit, train, support, and enable volunteers to work safely.

Methods Semi-structured interviews with patients and staff revealed a demand for volunteers in a befriending role. The appointment of a Care Team member to act as a link between the care team and volunteers was essential as previous attempts to introduce volunteers to care areas were unsuccessful. Volunteer roles were widely advertised and client centred interviews enabled us to select the right personalities and understand each applicant's skills. Volunteers are required to attend $26 \mathrm{~h}$ of training including familiarisation with the hospice before commencement.

Results The skill set and diversity of volunteers has added greatly to hospice life. Volunteers skills include massage, hairdressers, musicians, doctors, actors, and students thus expanding the range of services we can offer to guests. Committed volunteers may be offered the opportunity to undertake further training and fulfil an 'Advanced Volunteer' role.

Discussion The project has experienced challenges in ensuring that all staff embrace the benefits of care team volunteers. Introducing 'Managing Volunteers' training for staff helped to address this. Future plans include extended training and setting more rigorous induction to encourage only the most committed volunteers.

Conclusion With stringent selection, training and supervision care team volunteers can significantly enhance patient experience through normalisation and enhanced activities, an additional benefit has been the embedding of the hospice in our local community. 